\title{
OTIZM SPEKTRUM BOZUKLUĞU TEDAVISINDE BESLENME YAKLAŞIMLARI
}

\author{
Seda ÖNAL ${ }^{1}$ \\ Aslı UÇAR ${ }^{2}$
}

\section{ÖZET}

Yaygınlığı her geçen gün artmakta olan otizm spektrum bozukluğu, toplumsal iletişim ve etkileşimde güçlükler ve sınırlı-yineleyici davranış örüntülerindeki yetersizlikle kendini gösteren yaygın gelişimsel bozukluk olarak tanımlanmaktadır. Yapılan epidemiyolojik çalışmalara göre 2000 yılında her 150 doğumda bir görülürken günümüzde 68 çocukta bir görülmektedir. Nedeninin tam olarak bilinmeyişi ve sıkıı̆ının her geçen gün artışı otizm konusunda yapılan çalışmaları arttırmıştır. Otizmli bireylerin bağırsaklarının aşııı geçirgen olması ve beslenmelerinde seçici olmaları otizm tedavisinde beslenme yaklaşımlarının yararlı olabileceği görüşünü ortaya çıkarmıştır. Glutensiz-kazeinsiz diyet, ketojenik diyet, özel karbonhidrat diyeti, Feingold diyeti, Candida vücut ekoloji diyeti, elimine alerji diyeti ve yağ asidi, multivitamin, mineral, probiyotik takviyesi otizm tedavisinde kullanılan beslenme yaklaşımlarındandır. Bu derlemede, bilimsel ve kanıta dayalı güncel beslenme yaklaşımlarının otizm semptomları üzerindeki etkilerini değerlendirmek amaçlanmıştır.

Anahtar Kelimeler: Gida takviyeleri, glutensiz diyet, ketojenik diyet, otizm, tıbbi beslenme tedavisi

\section{Nutritional Approaches in the Treatment of Autism Spectrum Disorder}

\section{Abstract}

Autism spectrum disorder, which global prevelance is increasing day by day, is pervasive developmental disorder defined as deficiencies communication and interaction difficulties and limited-repetitive behaviour patterns. According to epidemiological studies, while prevelance was one in every 150 births in 2000, it is one each 68 children nowadays. The precise unknownness of the cause and the increasing of its frequency have increased the studies about autism. The fact that the intestines of autistic individuals are over-permeable and selective in their diet suggests that nutritional approaches may be beneficial in the treatment of autism. Gluten-free diet, ketogenic diet, special carbohydrate diet, Feingold diet, Candida body ecology diet, elimination allergy diet and fatty acid, multivitamin, mineral, probiotic supplementation are nutritional approaches used in autism

1 Araş.Gör. Ankara Üniversitesi Sağlık Bilimleri Fakültesi, Beslenme ve Diyetetik Böümü, edaonal89_90@hotmail.com

2 Doç.Dr. Ankara Üniversitesi Sağlık Bilimleri Fakültesi, Beslenme ve Diyetetik Böümü 
treatment In this review, it was aimed to evaluate the effects of current scientific and evidence based nutrition approaches on autism symptoms.

Keywords: Food supplements gluten free diet, ketogenic diet, autism, medical nutrition therapy

\section{GíRiş}

İlk kez 1943 yılında Leo Kanner tarafından "infantil otizm" diye adlandırılan (Kanner, 1943), Otizm Spektrum Bozukluğu (OSB) (Autism Spectrum Disorders, ASD), sosyal etkileşimde sözel olmayan iletişimsel davranışları, sosyal karşılıkta, sosyal iletişimde ve sosyal etkileşimde eksiklikleri kapsayan, çok yönlü durumlara karşı yetersizlik ve ilişkileri geliştirme, koruma ve anlamada kalıcı eksikliklerle karakterize olan bir spektrum rahatsızığı olarak tanımlanmaktadır. ${ }^{1}$ Biyolojik, psikolojik, nörolojik, genetik ve bağışıklıkla ilgili teoriler ileri sürülmüş olmasına rağmen, otizmin temel fizyopatolojisi bilinmemektedir. ${ }^{2}$ Etiyolojisinde kesin neden belirtilmemesine karşın genetik faktörlerin etkili olduğu görüşü hakimdir. ${ }^{3,4}$ Ancak OSB gelişiminde genetik etmenlere ek olarak çevresel etmenlerin de etkili olduğu bildirilmektedir. Bu çevresel etkenler arasında virüsler, radyasyona maruz kalma ve ilaç kullanımı sayılabilmektedir. ${ }^{5}$ İnsan beyninin toksik maddelere hassasiyeti ve doğum öncesi yaşanan maruziyetler ileri yaşlarda ortaya çıkan otizmle ilişkilendirilmektedir. ${ }^{6}$ Ayrıca annenin prenatal dönemde patojenler gibi inflamatuvar mediatörlere maruz kalması da otizm oluşumu ile bağlantılı olarak kabul edilmektedir. ${ }^{7}$ Anne ve babanın ileri yaşta olması da, birbirinden bağımsız olarak otizmle ilişkilendirilmektedir. ${ }^{8}$

Otizm belirtileri genellikle 3 yaştan önce ortaya çıkmakta ve tüm yaşam boyunca devam etmektedir., 90

Otizmin sıklığını belirlemeye yönelik ilk araştırma, İngiltere'de 19601970'lerde yapılmış ve sıklığı 10000 kişide 4-5 olarak belirlenmiştir. Daha sonra 1980 'lerde yaygın gelişimsel bozukluk için DSM-III tarama ve tanı ölçütleri kullanılmış, prevalans 3-18 yaş arasında 10.000 çocukta 3.3, 812 yaş arasında 10.000 çocukta 3.6 olarak belirlenmiştir. Yaygınlığı, toplumlar arasında da farklılık göstermektedir. ${ }^{11}$ Sağlık Kaynakları ve Servis Yönetimi (HRSA) otizm görülme sıklığını 110 kişide 1 olarak belirlerken, 11 toplulukta yapılan bir çalışmada (Arkansas, Wisconsin, Alabama, Arizona, Missouri, New Jersey, Georgia, Maryland, Utah, North Carolina and Colorado) sekizinci yaşta otizm prevalansı 68'de 1 olarak belirlenmiştir. ${ }^{12}$ Türkiye'de ise 44045 çocuk üzerinde yapılan Otizm Tarama Projesi kapsamında Erken Çocukluk Dönemi Otizm Tarama 
Ölçeği (M-CHAT) uygulanmış ve 242 çocuktan 49'unun orta derecede risk altında olduğu, 228 çocuktan 15 'inin ise yüksek risk altında olduğu belirlenmiştir. ${ }^{13}$ Yaygınlık oranları baz alınarak ülkemizde 500.000'in üzerinde otizmli birey ve zorunlu ilköğretim çağında yaklaşık 100.000 otizmli çocuk olduğu tahmin edilmektedir. ${ }^{14}$

OSB'li çocuklar sağlıklı çocuklarla karşılaştırıldıklarında aynı gelişim özelliklerini göstermediği ve otizmli çocukların duyusal özellikler açısından farklı oldukları bildirilmektedir. ${ }^{15,16} \mathrm{Bu}$ farklılıklar daha çok duyma ve dokunma duyularında görülmektedir. ${ }^{17}$

Otizmli çocuklarda beslenme problemleri yaygın olup, çiğneme güçlüğü, besin seçiciliği, takıntılı yeme gibi davranışlar sıklıkla görülmektedir. Bu sorunların çözümüne yönelik beslenme arayışları devam etmekte olup, bu çalışmada da OSB'li bireylerde uygulanan kanıta dayalı beslenme yaklaşımlarının özelliklerinin incelenmesi amaçlanmaktadır.

\section{Otizmli Çocuk Beslenmesinde Tedavi Yaklaşımları}

Otizmli çocukların bağırsaklarının aşırı geçirgen olmasının ve beslenmede çok seçici olmalarının sonucu olarak, pek çok vitamin ve mineral eksikliği yaşadıkları bildirilmektedir. ${ }^{18}$ Beslenme ve OSB arasındaki bağlantı, yeni bir bakış açısı sağlamış ve beslenmenin OSB etyolojisinde rol oynayabileceğini ve semptomları hafifleterek tedavide etkin rol oynayabileceğini göstermiştir. ${ }^{19}$ Buna yönelik beslenme desteği konusunda çeşitli tedavi yaklaşımları denenmektedir. Uygulanan bu tedavi yaklaşımları arasında Glutensiz-kazeinsiz Diyet (Gluten Free-Casein Free (GFCF)), ketojenik diyet, Özel Karbonhidrat Diyeti (Spesific Carbonhydrate Diet (SCD)), Feingold diyeti, Candida Vücut Ekoloji Diyeti (Candida Body Ecology Diet (BED)) diyeti ve elimine alerji diyetleri yer almaktadır. Ayrıca vitamin mineral suplemanları, probiyotik, yağ asitleri takviyesi gibi yardımcı tedaviler de uygulanmaktadır. Aşağıda bu diyetlerin özellikleri açıklanmıştır.

\subsection{Glutensiz- Kazeinsiz diyet (Gluten Free-Casein Free) GFCF}

Beslenmede önemli yeri olan tahıl ve ürünleri bazı hastalıklarda yasaklanabilmektedir. Tahıl kaynaklı hastalıklardan biri olan çölyak; buğday, çavdar, arpa ve bazen de yulaf ürünlerinin tüketimi sonucu bağırsakta ortaya çıkmaktadır. ${ }^{20}$ Çölyakta tek tedavi seçeneği olan glutensiz diyet otizmli bireylerde de kullanılmakta, ayrıca sütte bulunan kazein nedeniyle de tüm süt ve süt ürünlerinin (peynir, yoğurt, ayran vb.) otizmli çocukların diyetinden çıkarılmasının etkili olacağı düşünülmektedir. ${ }^{21}$ 
Gluten ve kazein içeren yiyeceklerin kusurlu bir şekilde çökmesiyle oluşan opioid peptitlere bağı olarak, bazı semptomların oluşabildiği hipotezi kurulmuştur. 'Sızıntılı barsak sendromu' olarak bilinen artmış bağırsak geçirgenliği, endojen opiat sistemini ve sinir sistemindeki nörotransmisyonu etkileyerek, bu peptitlerin barsak membranına, kan dolaşımına, kan beyin bariyerine geçişine izin vermektedir. Opioidin aşırı artmasının, otizmde oluşan davranışlara neden olduğu ve bu maddelerin diyette azalmasına bağlı olarak otistik davranışlarda iyileşmeler olduğu düşünülmektedir. ${ }^{22}$

Otistik çocukların aileleri tarafından başvurulan ve popüler bir uygulama olan gluten ve/veya kazeinden yoksun (GFCF) diyet, birbiriyle örtüşen 4 biyolojik teoriye dayanmaktadır. Birinci teori opioid fazlalığı, ikincisi azalmış peptidaz aktivitesi, üçüncüsü bağışıklık sistemindeki aksaklıklar veya otoimmünite, sonuncu teori ise gastrointestinal bozukluklardır. ${ }^{23}$ Otizmli çocukların barsak florasının bozulması, permeabilitesinin artması; bu nedenle beslenmeyle alınan gluten ve kazein proteinlerinin metabolize olmadan kana karışmasıyla kazeo- ve gluteo- morfine dönüştüğü görülmüştür. Morfinin gluteo- ya da kazeo- parçasının gastrointestinal sistemde semptomlara neden olduğu görüşü hakimdir. ${ }^{24} \mathrm{Bu}$ ilişki şekil 1'de görülmektedir.

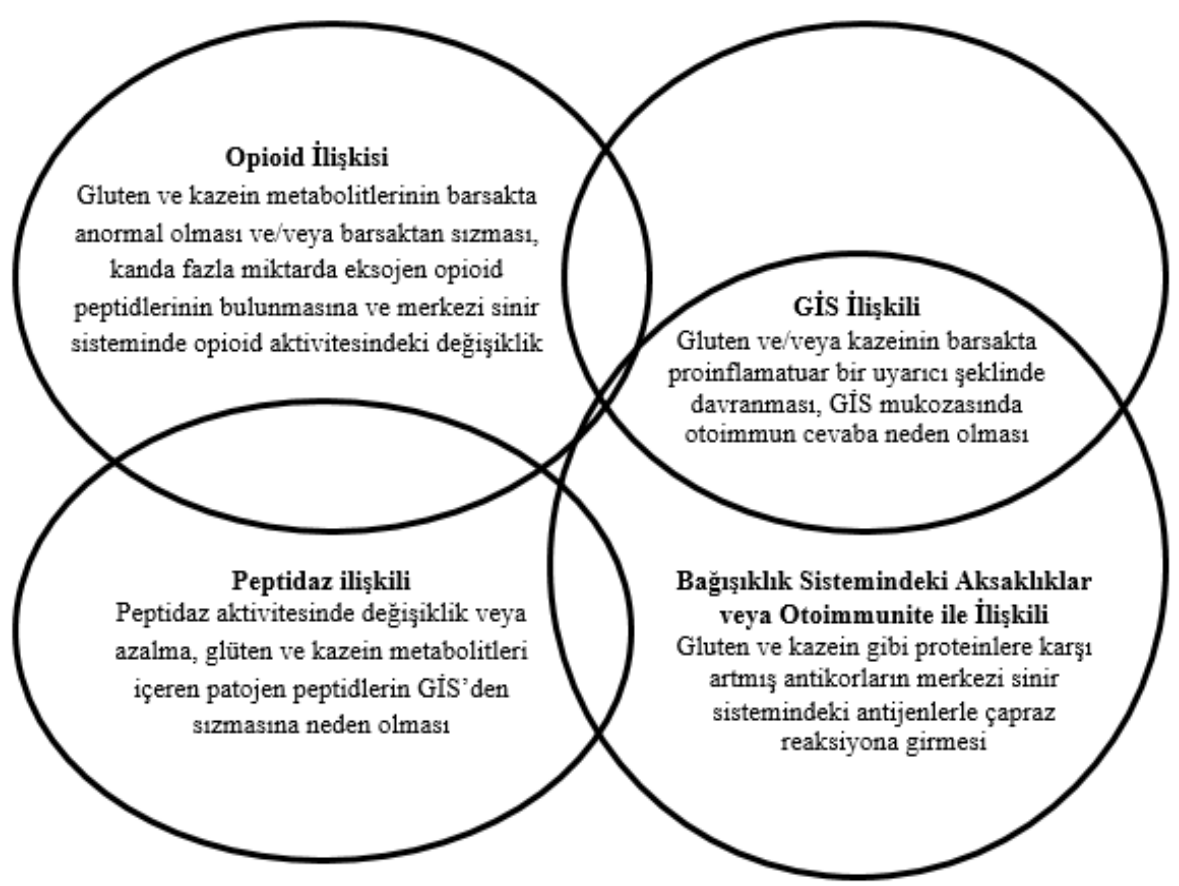

Şekil 1. Otizm Spektrum Bozukluklarında Eliminasyon Diyetleri ${ }^{25}$ 
Yapılan çalışmalarda kazeinsiz ve glutensiz diyetin otizmli çocukların davranışlarına etkileri incelenmiştir.

Pennesi ve Klein'in ${ }^{21} 2012$ 'de yaptığı çalışmada, 293 otistik çocuk ve ailesi çalışmaya dahil edilmiş ve çalışmaya katılan 223 çocuğa tamamen kazeinsiz/glutensiz diyet verilirken, 70 çocuğa kısmi diyet uygulanmıştır. Uygulanan diyet sonrası gluten ve kazeini tamamen kısıtlanan çocukların kısmi kısıtlanan gruba göre gastrointestinal semptomlarında, yiyecek alejilerinde, yiyeceğe karşı duyarlılıklarında azalma ve psikolojik, sosyal davranışlarında iyileşmeler olduğu belirlenmiştir. Glutensiz kazeinsiz diyetin pozitif etkileri olmasına rağmen, yapılan çalışmalar gözönüne alındığında şu an için net bir sonuca ulaşmak mümkün olamamaktadır.

\subsection{Ketojenik Diyet}

Otizm ve epilepsi arasındaki ilişki karmaşık olarak görülse de, OSB'li bireyler, normal gelişmekte olan bireylere kıyasla epilepsiye 3 ila 22 kat daha yatkın olup OSB'li bireylerin yaklaşık \% 25'i, yaşamlarının bir noktasında klinik nöbet geçirmektedir. ${ }^{26}$

Epileptik nöbetlerin sayısını ve şiddetini azaltmak için terapötik bir yöntem olarak tanımlanan ketojenik diyetin, zihinsel duruma bağlı davranışlar ve hiperaktivite için olumlu etki yaptığı görülmüştür. Uzun zincirli trigliserid diyeti olarak da bilinen klasik ketojenik diyette yağ, enerjinin büyük kısmını oluşturmakta, böylece vücut enerji kaynağı olarak yağı kullanmaya zorlanmaktadır. Protein günlük gereksinimin minimum kısmını oluştururken karbonhidratlar ciddi şekilde sınırlandırılmaktadır. Otistik davranışın, glikoz metabolizmasındaki bir bozuklukla ilişkili olduğu ve bunun sonucunda azalan nikotinamid adenin dinükleotit (NADH) veya nikotinamid dinükleotit eksikliğine (NAD) yol açtığı düşünülmektedir. Ketojenik diyetin NAD'dan tasarruf ederek mitokondriyal işlev sağlayacağı görüşü hakimdir. ${ }^{27}$

Ketojenik diyetin otizmde etkileri ile ilgili yapılan ilk çalışma, yaşları 410 arasında olan otistik davranışlar gösteren çocuklar üzerindedir. Otuz çocuğa, altı ay boyunca dört hafta aralıklarla ketojenik diyetin modifiye edilmiş hali olan John Radcliffe diyeti ve iki hafta normal kontrol diyeti uygulanmış, Katılımcılardan \%76,6'sı ketojenik diyete uyum sağlamıştır ve diyet müdahalesinden önce ve sonra Çocukluk Çağı Otizmi Değerlendirme Ölçeğini (CARS) tamamlamıştır. Araştırma sonucunda Radcliffe diyeti alan 18 katılımcıdan 10'unda iyileşme gözlemlenmiştir. ${ }^{28}$ Görüldüğü gibi ketojenik diyetin otizmde kesin bir tedavi şekli olduğuna dair kanıta dayalı bir çıkarım henüz yapılamamaktadır. 


\section{3. Özel Karbonhidrat Diyeti (Spesific Carbonhydrate Diet) (SCD)}

Özel karbonhidrat diyeti ilk olarak 1920'li yıllarda geliştirilmiştir. Hem basit hem de kompleks karbonhidratların malabsorbsiyonu göz önünde bulundurulmakta, buna bağlı olarak diyetteki kompleks karbonhidratlar kısıtlanırken basit karbonhidratlar tamamen çıkarılmaktadır. SCD'nin, irritabl barsak sendromu (IBS), çölyak hastalığı ve otizm gibi çeşitli hastalıklarda olumlu etki yaptığı görüşü hakimdir. ${ }^{29}$

SCD'nin amacı, hasar görmüş bağırsak duvarlarını ve bakteri üremesini kontrol altına almak, bağırsak patojenlerinin beslendiği karbonhidrat türlerini kısıtlamak ve böylece vücudun iç ekolojisini yani barsak florasını düzeltmektir. SCD, fermente besinlerin, özellikle ev yapımı yoğurtların ve probiyotiklerin kullanımını da teşvik etmektedir. ${ }^{30}$

SCD nişastaları yasaklamakta ve esas olarak et, tavuk, balık, yumurta, sebze, taze meyve, fındık ve yağlı tohumlardan oluşmaktadır. Diyet, sınırlı miktarda besin alımıyla başlamakta ve bağırsak yolları iyileştikçe kademeli olarak alınan besin miktarı arttırılmaktadır. ${ }^{31}$

\subsection{Feingold Diyeti}

Fenol, aromatik / benzen halkasıyla organik bir bileşik olan ve salisilatlarda doğal olarak bulunan ve yapay besin katkı maddelerinde olduğu gibi kimyasal olarak üretilen bir bileşiktir. Fenoller yapay olarak bir petrol türevinden yapılabilmekte, renklendirici ve koruyucu gıda katkı maddesi olarak kullanılmaktadır. ${ }^{32}$

Renklendirici ve koruyucuların ise çocuklarda hiperaktiviteye neden olabildiği bildirilmiştir. ${ }^{33}$ Fenol sülfür transferaz (PST) enzimindeki bozukluk nedeniyle otistik çocukların diyetinden de, renklendirici ve koruyucu içeren bu besinlerin veya domates gibi doğal salisilat içeren besinlerin çıkarılmasının olumlu etki yaptığı bildirilmiştir. ${ }^{34}$

$\mathrm{Bu}$ nedenle özellikle renklendirici, aroma verici, koruyucu Beta Hidroksi Asitler (BHA), Bütillendirilmiş hidroksi toluen (BHT), tersiyer bütil hidrokinon (TBHQ) ve tatlandırıcı içeren besinlerin diyetten çıkarılması, badem, elma, kayısı, çilek, salatalık, köri vb baharatlar, üzüm, kuru üzüm, portakal, bal, şeftali, biber ve domates gibi yaygın reaktif salisilat içeren besinlerin de kısıtlanması önerilmektedir. ${ }^{32}$ 
$\mathrm{Bu}$ öneriler yapılmakla birlikte Feingold diyetinin, otizmin semptomlarını hafifletmede etkinliğini gösteren, kanıta dayalı bir çalışma bulunmamaktadır. ${ }^{34}$

\section{(BED)}

1.5. Candida Vücut Ekoloji Diyeti (Candida Body Ecology Diet)

Candida albicans, maya benzeri bir mantar olup, özellikle bağışıklığı baskılanmış bireylerde enfeksiyonlara neden olabilmektedir. Candida albicans'ın aşırı artışı, otizmli çocuklarda görülen konsantrasyon bozukluğu, saldırganlık ve hiperaktif davranışlar gibi sorunlar ile ilişkilendirilmiş olup, baş ağrısı, mide sorunları, gaz ağrısı, yorgunluk veya depresyon ile de ortaya çıkabilmektedir. Antifungal ilaç alımları ve probiyotik etki sağlayan diyet takviyeleri, şekeri düşük diyetler koruyucu olarak uygulanmaktadır. ${ }^{35}$ Candida Vücut Ekoloji Diyeti, candidanın aşırı büyümesini temizlemek ve bağırsağın sağlığını desteklemek ve asit / baz dengesini sürdürmek için düşük asit oluşturan besinler ile, düşük şeker ve nişasta içeren ya da hiç şeker içermeyen kolay sindirilebilir besinleri, fermente besinleri ve diğer katı beslenme önerilerini içermektedir. BED, ham lahana turşusu ve diğer kültürlenmiş sebzeler, hayvansal olmayan sütle yapılan kefir ve yoğurt gibi birçok fermente besinleri içermektedir. BED, glutensiz olmasının yanı sıra, pirinçsiz, mısırsız ve soyasızdır. Diyette sadece kinoa, darı, kepekli buğday ve amarant (düzgünce ıslatıldığında) gibi birkaç besinin tüketimi serbesttir. ${ }^{32}$

\subsection{Elimine Alerji Diyetleri}

Otizmli çocukların çoğu, sindirim ve bağışıklık sistemindeki anormallikler nedeniyle besin hassasiyetine sahiptir. Sindirilmeyen karbonhidrat veya aminoasitler barsakta yararlı bakterilerin bu ögelere reaksiyon göstermesine yol açmaktadır ${ }^{36} \mathrm{Bu}$ nedenle eğer çocukta herhangi bir besin alerjisi veya intoleransı olduğu düşünülüyorsa gerekli testler yapılarak sorunun belirlenmesi önerilmekte ya da şüphelenilen besinin 2 haftalığına çıkartılması ve aynı besin diyete tekrar eklenerek alerjik semptomların meydana gelip gelmediğinin gözlenmesi gerekmektedir. ${ }^{37}$

Alerjik besinlerin diyetten çıkarılması, gastrointestinal sistemde, davranış ve dikkatin iyileştirilmesi de dahil olmak üzere, bazı çocuklarda iyileşmelere neden olabilmektedir. ${ }^{36}$ Diyetten çıkarılacak 
besinler arasında süt, buğday, soya, yumurta, yerfıstığı, fındık, balık ve kabuklu deniz ürünleri bulunmaktadır. ${ }^{37}$

\subsection{Besin ögesi takviyeleri}

Otizmli çocukların kronik ishal veya kabızlık, gastrointestinal inflamasyon ve sınırlı besin tercihi nedeniyle yeterli beslenemeyecekleri düşüncesinden yola çıkılarak yetersizliği belirlenen besin ögesinin supleman şeklinde alımı önerilmektedir. ${ }^{38}$ Otizmde etkili olduğu düşünülen besin ögesi takviyeleri aşağıda açıklanmıştır.

\subsubsection{Yağ asidi Takviyesi}

Otizmli çocuklarda omega-3 seviyesini gösteren güçlü kanıtlar olmamakla birlikte, bu çocuklarda n-6/n-3 oranının artmış olduğu görülmüştür. ${ }^{39}$

Otizmde karşılaşılan sorunların kısmi olarak vücutta omega-3 yağ asitlerinin eksikliği sonucu oluşabileceği ve supleman olarak alımının otizm semptomlarının iyileştirilmesine katkıda bulunacağı tahmin edilmektedir. ${ }^{5}$ Ancak bu konu ile ilgili yapılan sistematik bir çalışmada 143 makale incelenmiş ve omega-3 yağ asitleri takviyesinin OSB için etkili veya güvenli olup olmadığını belirleyen yeterli bilimsel kanıtın henüz mevcut olmadığı sonucuna varılmıştır. ${ }^{40}$ Ancak otizmli çocuklarda omega-3 seviyesini belirleyen güçlü kanıtlar olmamasına karşın, bu çocuklarda AA/EPA (Araşidonik asit / Eikosapentaenoik asit) oranının artmış olduğu rapor edilmiştir. ${ }^{41}$

Otizm ile omega-3 ve PUFA lar arasında bir ilişki olabileceği düşünülmüş ve otizmin tedavisinde omega-3'ün etkinliği deneysel olarak değerlendirilmeye başlanmıştır. ${ }^{42}$

Meguid ve arkadaşlarının ${ }^{43} 2008$ 'de yaptığı çalışmada 30 otizmli, 30 normal gelişen çocuk incelenmiş ve otizmli çocuklarda PUFA (Linolenik asit, dokozohegzonoik asit, araşidonik asit ve linoleik asit) seviyelerinin önemli derecede düşük olduğu görülmüştür. Otizmli çocuklara 3 ay boyunca hergün ikişer defa iki kapsül Efalex (omega 3 ve omega 6 içeren bir suplemen) isimli bir ilaç verilmiştir. Çalışma sonunda 20 otizmli çocukta ilaç kullanımına bağlı olarak PUFA seviyelerinde ve otistik davranışlarda iyileşmeler gözlenmiştir. 
Politi ve arkadaşlarının ${ }^{44} 2008$ 'de $18-40$ yaşları arasında 12 otizmli birey ile yaptıkları çalışmada ise, bireylere 6 hafta boyunca hergün 2 sefer olmak üzere $0.93 \mathrm{~g}$ EPA ve DHA, $5 \mathrm{mg} \mathrm{E}$ vitamini içeren balık yağı kapsülünden verilmiş ve bireylerin davranışlarını gözlemlenmiştir. Altı hafta sonunda otizmli bireylerde davranış problemlerinin sıklığı ve şiddetinde anlamlı bir iyileşme gözlenmemiştir.

\subsubsection{Multivitamin Takviyesi}

Çeşitli çalışmalarda, otizmli bireylerin vitamin ve mineral seviyelerinin düşük olduğu belirlenmiştir. ${ }^{45-47} \mathrm{Bu}$ eksikliğin kronik ishal/konstipasyon, gastrointestinal problemler veya diyet kısıtlamaları gibi nedenlerden kaynaklandığı ve immün sistemle ilişkili olabileceği düşünülmektedir. ${ }^{48}$ Ayrıca bu çocuklarda birçok metabolik sürecin, hem hücresel metilasyon hem de glutatyon aracılı antioksidan savunmanın eksik olduğu görülmüştür. Bu nedenle metionin transmetillasyon / transsülfürasyon metabolizmasında önemli bir kofaktör olan vitamin $\mathrm{B}_{12}$ 'nin metilasyonu ve antioksidan kapasitesini artıracağı düşünülmüştür. ${ }^{49}$ Ayrıca otizmde görülen artmış oksidatif stres, tedavide $C$ ve $E$ vitamini gibi antioksidan vitaminlerin kullanımı da yaygınlaştırmıştır. ${ }^{50}$

Yapılan bir çalışmada 14 yaşında otizmli bir erkek çocuğun kan bulgularına bakılmış, düşük $B_{12}$ vitamini ve yüksek homosistein seviyeleri görülmüş. Bu çocuğa ilk 5 gün $1000 \mu g B_{12}$ vitamini suplemanını takiben 8 hafta boyunca haftalık $1000 \mu \mathrm{g} B_{12}$ vitamini ve onu takiben ayda bir defa $B_{12}$ enjeksiyonu ve günlük $500 \mathrm{mg} C$ vitamini ve $400 \mathrm{mg}$ E vitamini verilmiştir. Çalışma sonunda çocukta daha iyi göz teması, tekrarlayan davranışlarda azalma, dokunma ve yürümede iyileşmeler gözlenmiştir. ${ }^{51}$

Yapılan başka bir çalışmada yaşları 3-8 arasında olan 20 otizmli çocuğa 3 ay boyunca verilen $C$ vitamini, $B_{6}$ vitamini desteğinin çocukların uyku problemlerinde, gastrointestinal sorunlarında iyileştirme sağladığı rapor edilmiştir. ${ }^{38}$

\subsubsection{Mineral Takviyesi}

Plazma çinko ve bakır düzeylerindeki farklılıkların, otizmli bireylerin çoğunda görülen aşırı hareketlilik, dürtüsellik ve konsantrasyon güçlüğü için bir neden olabileceği öngörülmüştür. ${ }^{52}$ 
Yorbik ve arkadaşlarının ${ }^{53} 2004$ yılında yaptıkları çalışma sonucunda otistik çocukların plazma, eritrosit ve çinko düzeylerinin sağlıklı çocuklardan daha düşük olduğu belirlenmiştir. Bunun nedeni serumda bakır/çinko seviyelerinin artışı ve buna bağlı olarak bakır çinko ve diğer metallerin düzenlenmesinde yer alan metallothioneinin proteinin artışı ile açıklanmıştır. Ancak bu durumun OSB"li çocuklarda disfonksiyona neden olabileceği belirtilmektedir. ${ }^{54}$

Vitamin / mineral takviyelerinin otizm için en çok önerilen tıbbi müdahaleler arasında yer aldığı bilinmekte fakat otizmli çocuklar için vitamin / mineral takviyeleri konusunda az sayıda tedavi çalışmasının yapıldığı bilinmektedir. ${ }^{55}$

\subsubsection{Probiyotik Takviyesi}

Otizmli her üç çocuktan birinde beslenme anormallikleri, gastroözofajiyal reflü, karın ağrısı, diyare, konstipasyon gibi çeşitli gastrointestinal sorunlar olduğu bilinmektedir. ${ }^{56,57} \mathrm{Bu}$ sorunlar otizmli çocuklarda sıklıkla anormal davranışlar ve olumsuz sosyal etkileşimler ile ilişkilendirilmiştir. ${ }^{58}$ Ancak çoğu zaman bu çocuklarda görülen anksiyete, şaşkınlık ve sosyal izolasyon, gastrointestinal şikayetleri gölgelemektedir. ${ }^{59}$ Konakladığı organizmanın sağlığına katkıda bulunan probiyotiklerin gut mikrobiyatasını değiştirerek sağlığı olumlu yönde etkilediği bilinmektedir. ${ }^{60}$ Otizmli çocuklarda ise potansiyel zararlı etkileri olan bazı metabolitlerin düzeylerini değiştirerek, problemlerin iyileşmesinde etkili olduğu tahmin edilmektedir. ${ }^{58}$ Probiyotik kullanımının yararı için ortaya atılan diğer bir hipotez, sağlıklı gut florasının gut-beyin bariyeri yoluyla beyin ve davranışlar üzerinde etkili olmasıdır. Ancak çalışmalardan elde edilen sonuçlar çelişkilidir. Kaluzna-Czaplinska ve Blaszczyk'nin ${ }^{61}$ 2012'de otizmli çocuklar üzerinde yaptıkları bir çalışmada; çocuklara iki ay boyunca Lactobacillus acidophilus içeren supleman verilmiş, müdahale grubunun kontrol grubuna göre bir işe odaklanma ve verilen işi yerine getirme kabiliyetlerinin arttığı belirlenmiştir. Ancak davranışsal olarak gruplar arasında herhangi bir farklılık belirlenmemiştir. Çift kör plasebo kontrollü yapılan başka bir çalışmada da benzer sonuçlar gözlenmiş, probiyotik kullanımının fekal mikrobiyata, gut fonksiyonu ve davranış skorları üzerinde olumlu etkileri olduğu saptanmıştır. ${ }^{62}$ Otizmli çocuklarda probiyotik kullanımı; gut mikrobiyatasını iyileştiren, inflamasyonu azaltan, epitelyal bariyer fonksiyonunu düzelten ve davranışsal semptomları iyileştiren terapötik bir yoldur. ${ }^{60}$ 


\section{SONUÇ VE ÖNERILER}

Bu çalışmada OSB'nin tedavisinde çeşitli tıbbi beslenme yaklaşımları ve konu ile ilgili çalışmalar incelenmiştir. Otizmi tedavi edebilecek belirli bir diyet müdahalesinin olmadığı ancak bazı özel diyet uygulamalarının ve takviyelerin bazı bireylerde olumlu davranış değişiklikleri sağladığı bulunmuştur. Uygulanan beslenme tedavilerinin otizm semptomlarını hafiflettiği şeker, katkı maddeleri, sindirilmesi zor nişasta içerikli yiyeceklerin ve çocuklarda alerjik reaaksiyon yaratan gıdaların ise ağırlaştırdığı görülmüştür. Ancak yapılan çalışmalar tedavide tam etkinlik sağlamadığı için uygulanan herhangi bir diyet tedavisinin tam etkin olduğunu söylemek şu an için mümkün olamamaktadır. Uygulanan diyetlerde her zaman bireysel ayrıcalıklar söz konusudur. Otizm etiyolojisi kesin olarak bilinmese de tedavisinde son yıllarda uygulanan beslenme yaklaşımları, otizm semptomlarını yönetmek için uygun beslenmenin önemini vurgulamaktadır. Otizmli bireylere uygun bir beslenme planı hazırlamadan ve ilgili öneriler yapılmadan önce geniş örneklem büyüklüğüne sahip başka prospektif kontrollü çalışmalara ihtiyaç duyulmaktadır.

\section{KAYNAKLAR}

1. American Psychiatric Association (APA) [Online]. Cautionary statement for forensic use of DSM-5. In Diagnostic and statistical manuel of mental disorders (5th ed.), (2013), Available From: http://dx.doi.org/10.1176/ appi.books.9780890425596, (Accessed 2017 April 08).

2. Özlü Fazlıoğlu, Y. Duyusal entegrasyon programının otizmli çocukların duyusal ve davranış problemleri üzerine etkisinin incelenmesi, Yayınlanmamış Doktora Tezi, 2004, Ankara Üniversitesi, Sosyal Bilimler Enstitüsü, Ankara.

3. Kim, Y.S., Leventhal, B.L. Genetic epidemiology and insights into interactive genetic and environmental effects in autism spectrum disorders. Biological psychiatry, 2015; 77(1): 66-74.

4. Mazefsky, C.A., Goin-Kochel, R.P., Riley, B.P., Maes, H.H. Genetic and environmental influences on symptom domains in twins and siblings with autism. Research in Autism Spectrum Disorders, 2008; 2(2): 320-331.

5. Özeren, S.G. Otizm Spektrum Bozukluğu (OSB) ve Hastalığa Kanıt Penceresinden Bakış. ACU Sağlık Bil Derg, 2013; 4(2): 57-63.

6. Landrigan, P.J. What causes autism? Exploring the environmental contribution. Curr Opin Pediatr, 2010; 22(2): 219-225. 
7. Parker-Athill, E.C., Tan, J. Maternal immune activation and autism spectrum disorder: interleukin-6 signaling as a key mechanistic pathway, Neurosignals, 2010; 18(2): 113-128.

8. Durkin, M.S., Maenner, M.J., Newschaffer, C.J., Lee, L.C., Cunniff, C.M., Daniels, J.L., Kirby, R.S., Leavitt, L., Miller, L., Zahorodny, W., Schieve, L.A. Advanced parental age and the risk of autism spectrum disorder. Am J Epidemiol, 2008; 168(11): 1268-1276.

9. Biçer, A.H., Alsaffar, A.A. Body mass index, dietary intake and feeding problems of Turkish children with autism spectrum disorder (ASD)." Res Dev Disabil, 2013; 34(11): 3978-3987.

10. Chen, M.H., Wei, H.T., Chen, L.C., Su, T.P., Bai, Y.M., Hsu, J.W., Huang, L.E., Chang, W.H., Chen, T.J., Chen, Y.S. (2015). Autistic spectrum disorder, attention deficit hyperactivity disorder, and psychiatric comorbidities: A nationwide study. Res Autism Spectr Disord, 2015; 10: $1-6$.

11. CDC [Online]. 10 Things to Know About New Autism Data. Available from: http://www.cdc.gov/features/dsautismdata/index.html, (2017a), (Accessed 2017 June 09).

12. Colson, A.S. Framing Autism Causes and Prevelance: A Content Analysis of Television Evening News Coverage--1994 Through April 2010, Thesis, 2010, Georgia State University.

13. T.C. Sağlık Bakanlığı, Tohum Otizm Vakfı. Otizm Tarama Projesi Sonuç Raporu (Online). Available from: http://tohumotizm.org.tr/sites/default/ files/kcfinder/files/Saglik\%20Bakanligi\%20Otizm\%20Platformu\%20Tara ma\%20Projesi\%20Raporu.pdf, 2008, (Accessed 2017 May 15).

14. T.C. Sağlık Bakanlığı, Tohum Otizm Vakfı. Turkiye'de otizm spektrum bozuklukları ve özel egitim. Available from: http://tohumotizm.org.tr/sites/ default/files/kcfinder/files/Turkiyede\%200tizm\%20Spektrum\%20Bozukl uklari\%20ve\%20Ozel\%20Egitim\%20(Haziran\%202010\%20).pdf., 2010, (Accessed 2017 May 18).

15. Kern, J.K., Trivedi, M.H., Garver, C.R., Grannemann, B.D., Andrews, A.A., Savla, J.S., Johnson, D.G., Mehta, J.A., Schroeder, J.L. The pattern of sensory processing abnormalities in autism. Autism, 2006; 10(5): 480494.

16. Tekin Iftar, E., Kırcaali-Iftar, G., Sucuoğlu, B., Kurt, O., Akmanoğlu, N., Değirmenci, H.D., Odluyurt, S. (2012). Otizm Spektrum Bozukluğu Olan Çocuklar ve Eğitimleri, Ed. Tekin-Iftar E, Ankara: Vize Yayıncılık, 2012; 102-120. 
17. Tomchek, S.D., Dunn, W. Sensory processing in children with and without autism: a comparative study using the short sensory profile. Am J Occup Ther, 2007; 61(2): 190-200.

18. Kałużna-Czaplıńska, J., Socha, E., Rynkowskı, J. B. vitamin supplementation reduces excretion of urinary dicarboxylic acids in autistic children. Nutrition research, 2011; 31(7): 497-502.

19. Cekici, H., Sanlıer, N. Current nutritional approaches in managing autism spectrum disorder: A review. Nutr Neurosci, 2017; 1-11.

20. Türksoy, S., Özkaya, B. Gluten ve Çölyak Hastalığı. Türkiye 9. Gıda Kongresi, 2006; 807-810.

21. Pennesi, C.M., Klein, L.C. Effectiveness of the gluten-free, casein-free diet for children diagnosed with autism spectrum disorder: based on parental report. Nutr Neurosci, 2012; 15(2): 85-91.

22. Marcason, W. What is the current status of research concerning use of a gluten-free, casein-free diet for children diagnosed with autism? J Am Diet Assoc, 2009; 109(3): 572.

23. Şişmanlar, Ş.G., Karakaya, I., Yıldız Öç, Ö. New Therapeutic Pursuits On The Autistic Disorder: Gastrointestinal System. Turk J Chıld Adolesc Ment Health, 2010; 17(1): 51-58.

24. Keskin, S., Alkış, H. Otizm Ve Pediatrist. Yeni Symposium, 2001, 39: 3538.

25. Christison, G.W., Ivany, K. Elimination diets in autism spectrum disorders: any wheat amidst the chaff?. J Dev Behav Pediatr, 2006, 27(2): 162-171.

26. Frye, R.E., Sreenıvasula, S., Adams, J.B. Traditional and non-traditional treatments for autism spectrum disorder with seizures: an on-line survey. BMC Pediatr, 2011; 11(1), 37.

27. Neggers, Y. [Online]. Dietary Interventions in Autism. Available from: https://www.res4 earchgate.net/publication/221915783, 2011, (Accessed 2017 June 16).

28. Evangeliou, A., Vlachonikolis, I., Mihailidou, H., Spilioti, M., Skarpalezou, A., Makaronas, N., Propiou, A., Christodoulou, P., Liapi-Adamidou, G., Helidonis, E., Sbyrakis, S., Smeiting, J., Christodoulou, P. Application of a ketogenic diet in children with autistic behavior: pilot study. J Child Neurol, 2003; 18(2): 113-118.

29. Cohen, S.A., Gold, B.D., Oliva, S., Lewis, J., Stallworth, A., Koch, B., Eshee, L., Mason, D. Clinical and mucosal improvement with specific carbohydrate diet in pediatric Crohn disease. J Pediatr Gastroenterol Nutr, 2014; 59(4): 516-521. 
30. Autism Canada (Online). Available from: http://autismcanada.org/livingwith-autism/treatments/biomedical/diets/specific-carbohydrate-diet, (Accessed 2017 June 16).

31. Brighttots (Online) Available from: http://www.brighttots.com/ Autism_Diet/Specific_Carbohydrate_Diet.html, (Accessed 2017 May 08).

32. Matthews, J. (Online). Autism Diets: The First Step to Biomedical Intervention and Autism Recovery. Available from: http://www. generationrescue.org/resources/, 2013, (Accessed 2017 June 01).

33. Mccann, D., Barrett, A., Cooper, A., Crumpler, D., Dalen, L., Grimshaw, K., Kitchin, E., Lok, K., Porteous, L., Prince, E., Sonuga-Barke, E, O Warner, J., Stevenson, J. Food additives and hyperactive behaviour in 3year-old and 8/9-year-old children in the community: a randomised, double-blinded, placebo-controlled trial. The lancet, 2007; 370(9598): 1560-1567.

34. American Academy Of Pediatrics (Online). Available from: https://www.kennedykrieger.org/sites/default/files/star_training/cardstar-asd-special-diets-factsheet.pdf. (Accessed 2017 June 18).

35. Kałużna-Czaplińska, J., Jóźwik-Pruska, J. Nutritional strategies and personalized diet in autism-choice or necessity?. Trends Food Sci Technol, 2016; 49: 45-50.

36. Adams, J.B. (Online). Summary of Dietary, Nutritional, and Medical Treatments for Autism-based on over 150 published research studies. ARI publication, 40, Available from: http://autism.asu.edu, 2013, (Accessed 2017 June 18).

37. Strickland, E., Mccloskey, S. Eating for autism: The revolutionary 10-step nutrition plan to help treat your child's autism, Asperger's, or ADHD. Da Capo Lifelong Books, 2009.

38. Adams, J.B., Holloway, C. Pilot study of a moderate dose multivitamin/mineral supplement for children with autistic spectrum disorder. J Altern Complement Med, 2004; 10(6): 1033-1039.

39. Vancassel, S., Durand, G., Barthelemy, C., Lejeune, B., Martineau, J., Guilloteau, D., Andres, C., Chalon, S. Plasma fatty acid levels in autistic children. Prostaglandins Leukot Essent Fatty Acids, 2001; 65(1): 1-7.

40. Bent, S., Bertoglio, K., Hendren, R.L. Omega-3 fatty acids for autistic spectrum disorder: a systematic review. J Autism Dev Disord, 2009; 39(8): 1145-1154.

41. Watson, R.R., De Meester, F. (2014). Omega-3 Fatty Acids in Brain and Neurological Health. Edit. Watson RR. USA: Elsevier; 350-355. 
42. Karr, J.E., Alexander, J.E., Winningham, R.G. Omega-3 polyunsaturated fatty acids and cognition throughout the lifespan: a review. Nutr Neurosci, 2011; 14(5): 216-225.

43. Meguid, N.A., Atta, H.M., Gouda, A.S., Khalil, R.O. Role of polyunsaturated fatty acids in the management of Egyptian children with autism. Clinical Biochemistry, 2008; 41(13): 1044-1048.

44. Politi, P., Cena, H., Comelli, M., Marrone, G., Allegri, C., Emanuele, E., Di Nemi, Su. Behavioral effects of omega-3 fatty acid supplementation in young adults with severe autism: an open label study. Arch Med Res, 2008; 39(7): 682-685.

45. Bener, A., Khattab, A.O., Al-Dabbagh, M.M. Is high prevalence of Vitamin $D$ deficiency evidence for autism disorder?: In a highly endogamous population. J Pediatr Neurosci,2014; 9(3): 227.

46. Stewart, P.A., Hyman, S.L., Schmidt, B.L., Macklin, E.A., Reynolds, A., Johnson, C.R., Jill, James, S., Manning-Courtney, P. Dietary supplementation in children with autism spectrum disorders: common, insufficient, and excessive. J Acad Nutr Diet, 2015; 115(8): 1237-1248.

47. Xia, W., Zhou, Y., Sun, C., Wang, J., Wu, L.A. preliminary study on nutritional status and intake in Chinese children with autism. Eur $\mathrm{J}$ Pediatr, 2010; 169(10): 1201-1206.

48. Kawicka, A., Regulska-llow, B. How nutritional status, diet and dietary supplements can affect autism. A review. Rocz Panstw Zakl Hig, 2013, 64(1), 1-12.

49. Hendren, R.L., James, S.J., Widjaja, F., Lawton, B., Rosenblatt, A., Bent, S. Randomized, placebo-controlled trial of methyl B12 for children with autism. J Child Adolesc Psychopharmacol, 2016; 26(9), 774-783.

50. Mazlum, B. Antioksidan Vitaminler ve Psikiyatride Kullanımı. Psikiyatride Güncel Yaklaşımlar, 2012; 4(4), 486-505.

51. Malhotra, S., Subodh, B.N., Parakh, P., Lahariya, S. Brief report: childhood disintegrative disorder as a likely manifestation of vitamin B12 deficiency. J Autism Dev Disord, 2013, 43(9), 2207-2210.

52. Yorbık, Ö., Olgun, A., Kırmızıgül, P., Akman, Ş. Dikkat eksikliği hiperaktivite bozukluğu olan erkek çocuklarda plazma çinko ve bakır düzeyleri. Klinik Psikiyatri, 2004a; 7: 80-84.

53. Yorbık, Ö., Olgun, A., Kırmızıgül, P., Akman, Ş. Karşı olma karşı gelme bozukluğunda plazma çinko ve bakır düzeyleri. Turk Psikiyatri Derg, 2004b; 15(4): 276-281.

54. Bjørklund, G. The role of zinc and copper in autism spectrum disorders. Acta Neurobiol Exp, 2013; 73(2): 225-236. 
55. Adams, J.B. Vitamin/Mineral Supplements for Children and Adults with Autism. Vitam Miner, 2015; 3(127), 2376-1318.

56. Horvath, K., Perman, J.A. Autism and gastrointestinal symptoms. Curr Gastroenterol Rep 2002; 4(3): 251-258.

57. Molloy, C.A., Manning-Courtney, P. Prevalence of chronic gastrointestinal symptoms in children with autism and autistic spectrum disorders. Autism, 2003; 7(2): 165-171.

58. Navarro, F., Liu, Y., Rhoads, J.M. Can probiotics benefit children with autism spectrum disorders?. World J Gastroenterol, 2016; 22(46): 10093-10102.

59. Nikolov, R.N., Bearss, K.E., Lettinga, J., Erickson, C., Rodowski, M., Aman, M.G., Mccracken, J.T., Mcdougle, C.J., Tierney, E., Vitiello, B., Arnold, L.E., Shah, B., Posey, D.J., Ritz, L., Scahill, L. Gastrointestinal symptoms in a sample of children with pervasive developmental disorders. J Autism Dev Disord, 2009; 39(3): 405-413.

60. Critchfield, J.W., Van Hemert, S., Ash, M., Mulder, L., Ashwood, P. The potential role of probiotics in the management of childhood autism spectrum disorders. Gastroenterol Res Pract 2011: 1-8.

61. Kałużna-Czaplińska, J., Błaszczyk, S. The level of arabinitol in autistic children after probiotic therapy, Nutrition, 2012; 28(2): 124-126.

62. Parracho, H.M., Gibson, G.R., Knott, F., Bosscher, D., Kleerebezem, M., Mccartney, A.L. A double-blind, placebo-controlled, crossover-designed probiotic feeding study in children diagnosed with autistic spectrum disorders. Int J Probiotics Prebiotics, 2010; 5(2): 69. 